DOI 10.11603/IJMMR.2413-6077.2017.1.7923

\title{
FREE RADICALS AND INFLAMMATION IN RATS OF DIFFERENT AGE IN CASES OF SODIUM NITRITES AND TOBACCO SMOKE POISONING
}

\author{
P. H. Lykhatskyi, L. S. Fira \\ I. HORBACHEVSKY TERNOPIL STATE MEDICAL UNIVERSITY, TERNOPIL, UKRAINE
}

Background. Due to the wide use of nitrate fertilizers in agriculture and their migration into groundwater and food, the spreading of nitrate poisoning has become epidemic. However, people in the process of life get into bad habits: smoking, alcohol, drugs abuse. All these factors affect health and can cause fatal outcome. In real life, people are often exposed to more toxic factors that lead to general poisoning of the body and damage of many organs.

Objective. The research was aimed to study the activity of free radicals and inflammation in rats of different age in cases of sodium nitrite affection with underlying 45-day tobacco intoxication.

Methods. The content of nitrite ion $\left(\mathrm{NO}_{2}^{-}\right)$was evaluated by Gris reaction. The level of pro-inflammatory (interleukin 6 (IL-6) and anti-inflammatory (interleukin 4 (IL-4) cytokines was determined in serum by ELISA method using test kits.

Results. It was proved that in rats of different age affected by sodium nitrite with underlying 45-day tobacco smoke intoxication, the content of nitrite ion in serum, liver, lungs and myocardium is increased. After poisoning the animals with the studied toxicants, inflammation was activated in the body that was evidenced by the increased pro-inflammatory cytokine IL-6 and decreased inflammatory cytokine IL-4 in serum.

Conclusions. The nitrite ion content in organs was the most significant and inflammation was manifested in the immature rats. In these animals the content of anti-inflammatory cytokines was the lowest.

KEY WORDS: tobacco smoke; sodium nitrite; rats of different age; nitrite ions; cytokines.

\section{Introduction}

The wide spread smoking is a global problem of humanity; many scientists and experts make efforts to solve it. Smoking has a negative impact on the health of the smokers, but also on the health state of people, who do not smoke but are exposed to harmful effects of pollutants entering the atmosphere with tobacco smoke [1]. Numerous scientific studies clearly highlighted the negative influence of smoking on the development of many diseases of different organs and systems of the human body $[2,3]$.

In recent years, the influence of smoking on free radical processes on the body has been extensively studied. It is established that smoking causes depletion of vitamins $C$ and $A$, decreases serum levels of other antioxidants, which leads to tissue damage by free radicals $[4,5]$. Study of the oxidation-antioxidant status

Corresponding author: Petro Lykhatskyi, Department of Medical Biochemistry, I. Horbachevsky Ternopil State Medical University, 1 Maidan Voli, Ternopil, Ukraine, 46001 Phone number: +380974433614

E-mail: luhatsky@tdmu.edu.ua in passive smokers revealed similarity of such changes in active smokers [6].

Due to the increasing technogenic and anthropogenic pollution, the study of combined effects on the body of the most common xenobiotics: heavy metals, nitrates and nitrites, tobacco smoke, medications, is urgent. Considerable attention is attracted to intoxication mechanism of nitrite and nitrate. This happens because of the intensive application of chemicals in the industry, lack of efficient methods for purifying drinking water, high levels of pollution caused by nitrates and nitrites number in foods, especially early fruits and vegetables. Hemic hypoxia, caused by nitrates that penetrate into the body, cause functional and morphological changes in many organs, including kidneys and liver, which can lead to further development of comorbidity $[7,8]$.

Because of the summation of environmental risk factors, chronic inflammation may develop, which involves all organs and tissues.

Recently, the attention of researchers has been attracted to mediators of immune re- 
sponses - cytokines. Cytokines are produced by all body cells for cell-to-cell interaction and regulation of biochemical processes in cell [9]. Imbalance of cytokines is important for the pathogenesis of toxic affection of the body.

The aim of this research was to study the activity of free radicals and inflammation in rats of different age in cases of sodium nitrite affection with underlying 45-day tobacco intoxication.

\section{Methods}

The experiments were conducted on white outbred male rats that were kept on a standard diet at the vivarium of Ternopil State Medical University. The rats were divided into three age groups: the first - immature, weighing $60-80 \mathrm{~g}$, the second - mature, weighing $180-200 \mathrm{~g}$, the third - senile rats, weighing 300-320 g; each age group consisted of two subgroups: an intact control and experimental group. Rats study groups were affected with tobacco smoke for 45 days. The test animals were divided into 3 groups. One of them was administered with sodium nitrite, dose $45 \mathrm{mg} / \mathrm{kg} 24$ hours before the end of the experiment; the second - with sodium nitrite 72 hours before euthanasia. The third group of rats was subjected to toxic affection with tobacco smoke only. Depending on the chronic smoke effect, the model was simulated using a sealed chamber 30 litres in volume, allowing fumigating the animals in free behaviour. Tobacco smoke, formed by combustion of 6 cigarettes "Prima sribna (blue)", containing $0.6 \mathrm{mg}$ of nicotine and $8 \mathrm{mg}$ of tar, was served into it through openings in the chamber. The camera was located 6 animals both within 6 minutes. The animals in the control group were well for 6 minutes in a sealed chamber, but were not subject to smoke.

In 45 days after the beginning of the affection of the animals with tobacco smoke they were taken out of the experiment by euthanasia under thiopental anaesthesia.

Blood, serum, liver, lungs and myocardium of the animals were used for the study. The experimental tissues were used to prepare $10 \%$ homogenates using saline.

The content of nitrite ion (NO-2) was determined by Gris reaction [10].

Pro-inflammatory (interleukin 6 (IL-6) and anti-inflammatory (interleukin 4 (IL-4) cytokines levels in blood serum were determined by ELISA methods using test kits. Quantitative assessment of serum concentration in peripheral blood of these cytokines was performed by chemiluminescent enzyme-linked immunosorbent assay using ELISA analyser RT-2100C. Test systems and control serum IL-4, IL-6, Russia, were used according to the test systems protocols. The results of the reaction were determined by a spectrophotometer ULAB$108 \mathrm{UA}$, wavelength $450 \mathrm{~nm}$. These cytokines concentration was evaluated using a calibration curve in picogram per $1 \mathrm{ml}(\mathrm{pg} / \mathrm{ml})$ [11].

The research was performed according to the general principles of animal experiments approved by the National Congress on Bioethics (2001, Kyiv, Ukraine) and is consistent with the regulations of the European Convention for the Protection of Vertebrate Animals Used for Experimental and Other Scientific Purposes (Strasbourg, France, 1985) [12]. Statistical analysis of the data was performed using STATISTICA 6.0, parametric Student's t-test and nonparametric Wilcoxon criterion for related samples. Changes considered significant at $p \leq 0.05$ [13].

\section{Results}

After rats poisoning with sodium nitrite (SN) during a 45-day tobacco smoke (TS) toxicity we have noticed the increase in content of nitrite ion in serum and organs (Table 1).

In immature rats nitrite ion content in serum increased by $18 \%$ till 45 day of TS toxicity. After the poisoning with sodium nitrite (24 hours before the end of the experiment on the $45^{\text {th }}$ day) the content of this indicator increased by $69 \%$, and after the application of toxicants in 72 hours before the study deadline the content of nitrite ion increased by $132 \%$.

A similar increase in nitrite ion content was evidenced in serum of mature and old rats. Using of both toxicants led to increase in its content in 2 times ( 72 hours after 45-day SN poisoning of TS animals).

In liver of rats of all age, nitrite ion content increased after the affection with tobacco smoke. The use of sodium nitrite as an additional toxicant contributed to the formation of nitrite ion. In liver of the immature rats the rate increased in 3 times, in mature - in 3.5 times. The least sensitive liver was evidenced in the senile animals which nitrite ion content increased in 2.2 times in the final period of the study.

Similar dynamics was observed in lungs of rats of different age. The highest content of nitrite ion was in the groups of rats with underlying 45 day tobacco intoxication which 72 hours before the end of the experiment were administered with sodium nitrite. This rate 
Table 1. The content of nitrite ion in serum ( $\mathrm{nmol} / \mathrm{L})$ and organs $(\mathrm{nmol} / \mathrm{kg})$ of rats of different age affected by sodium nitrite with underlying $\mathbf{4 5}$ day tobacco smoke toxicity $(M \pm m ; n=72)$

\begin{tabular}{|c|c|c|c|}
\hline \multirow{2}{*}{ Research time, days } & \multicolumn{3}{|c|}{ Groups of experimental animals } \\
\hline & immature rats & mature rats & senile rats \\
\hline & \multicolumn{3}{|c|}{ blood serum } \\
\hline intact rats & $10.00 \pm 0.46$ & $8.20 \pm 0.74$ & $8.80 \pm 0.56$ \\
\hline 45 day affection with tobacco smoke & $11.80 \pm 0.44^{*}$ & $10.20 \pm 0.18$ & $10.70 \pm 0.46$ \\
\hline $\begin{array}{l}45 \text { day affection with tobacco smoke }+ \\
24 \text { hours sodium nitrite poisoning }\end{array}$ & $16.90 \pm 0.87 *$ & $15.30 \pm 0.22 *$ & $15.80 \pm 0.29 *$ \\
\hline \multirow[t]{2}{*}{$\begin{array}{l}45 \text { day affection with tobacco smoke }+ \\
72 \text { hours sodium nitrite poisoning }\end{array}$} & $23.20 \pm 0.37 *$ & $16.40 \pm 0.25 *$ & $17.90 \pm 0.18 *$ \\
\hline & \multicolumn{3}{|c|}{ Liver } \\
\hline intact rats & $7.60 \pm 0.22$ & $3.20 \pm 0,16$ & $9.90 \pm 0.39$ \\
\hline 45 day affection with tobacco smoke & $10.20 \pm 0.61 *$ & $5.40 \pm 0.51$ * & $11.40 \pm 0.43 *$ \\
\hline $\begin{array}{l}45 \text { day affection with tobacco smoke }+ \\
24 \text { hours sodium nitrite poisoning }\end{array}$ & $15.60 \pm 0.21$ * & $11.00 \pm 0.29 *$ & $16.10 \pm 0.79 *$ \\
\hline \multirow[t]{2}{*}{$\begin{array}{l}45 \text { day affection with tobacco smoke }+ \\
72 \text { hours sodium nitrite poisoning }\end{array}$} & $23.00 \pm 0.59 *$ & $11.30 \pm 0.48 *$ & $21.50 \pm 0.73 *$ \\
\hline & \multicolumn{3}{|c|}{ Lungs } \\
\hline intact rats & $1.30 \pm 0.14$ & $1.00 \pm 0.11$ & $1.70 \pm 0.19$ \\
\hline 45 day affection with tobacco smoke & $2.90 \pm 0.28 *$ & $1.60 \pm 0.14 *$ & $2.60 \pm 0.23 *$ \\
\hline $\begin{array}{l}45 \text { day affection with tobacco smoke }+ \\
24 \text { hours sodium nitrite poisoning }\end{array}$ & $3.40 \pm 0.31$ * & $1.90 \pm 0.11$ * & $3.10 \pm 0.17 *$ \\
\hline \multirow[t]{2}{*}{$\begin{array}{l}45 \text { day affection with tobacco smoke }+ \\
72 \text { hours sodium nitrite poisoning }\end{array}$} & $4.80 \pm 0.21 *$ & $3.20 \pm 0.13 *$ & $4.60 \pm 0.32 *$ \\
\hline & \multicolumn{3}{|c|}{ Lungs } \\
\hline intact rats & $2.20 \pm 0.14$ & $1.60 \pm 0.15$ & $1.80 \pm 0.15$ \\
\hline 45 day affection with tobacco smoke & $4.00 \pm 0.26 *$ & $2.70 \pm 0.14 *$ & $3.40 \pm 0.14^{*}$ \\
\hline $\begin{array}{l}45 \text { day affection with tobacco smoke }+ \\
24 \text { hours sodium nitrite poisoning }\end{array}$ & $4.40 \pm 0.21 *$ & $2.90 \pm 0.17 *$ & $3.70 \pm 0.20 *$ \\
\hline $\begin{array}{l}45 \text { day affection with tobacco smoke }+ \\
72 \text { hours sodium nitrite poisoning }\end{array}$ & $4.90 \pm 0.16 *$ & $3.20 \pm 0.13 *$ & $4.10 \pm 0.13 *$ \\
\hline
\end{tabular}

Note: here and in the following tables * - significant changes between intact rats and rats affected with tobacco smoke $(p \leq 0.05)$.

increased in the immature rats in 3.7 times, in the mature - in 3.2 times, and in the senile - in 12.7 times compared with the intact control group.

During the study of myocardium of the smoke intoxicated rats almost the same increase in the content of nitrite ion in all age groups (in 1.7-1.9 times higher than normal) was noted. In the rats poisoned with both toxicants this rate also increased: in the immature and old rats it exceeded the intact control in 2.2-2.3 times respectively. In the mature rats the rate increase in myocardium exceeded 2 times.

Thus, the poisoning of rats for 45 days with tobacco smoke caused a moderate increase in nitrite ion content in blood serum and organs of rats of different age. After an additional affection of rats with sodium nitrite, this rate significantly increased $(r \leq 0.05)$ and was considerably higher than in the intact animals. This increase in the content of nitrite ion may be caused by activation of free radical processes in the affected organism.

We determined the content of pro- and anti-inflammatory cytokines in blood serum of rats after simultaneous affection with sodium nitrite and tobacco smoke. The results of the study of pro-inflammatory cytokine (IL-6) content in blood of rats of different age groups are presented in Table 2.

In old rats inflammation development was less significant, as evidenced by the increase of IL- 6 content in serum after the affection with tobacco smoke in 2.4 times, and after the application of both toxicants in 2.6 times (at the end of the experiment).

Most inflammation was activated in the immature rats. Poisoning of the young animals with tobacco smoke resulted in pro-inflammatory cytokine increase in 3.4 times. In the smoke affected animals, which 72 hours before 
Table 2. The content of pro-inflammatory cytokines (IL-6) in serum (ng/L) of rats affected with sodium nitrite with underlying 45-day tobacco smoke toxicity $(M \pm m ; n=72)$

\begin{tabular}{|l|c|c|c|}
\hline \multirow{2}{*}{ Research time, days } & \multicolumn{2}{c|}{ Groups of experimental animals } \\
\cline { 2 - 4 } & immature rats & mature rats & senile rats \\
\hline intact rats & $1.91 \pm 0.28$ & $3.00 \pm 0.30$ & $4.14 \pm 0.17$ \\
\hline 45 day affection with tobacco smoke & $6.43 \pm 0.21 *$ & $8.31 \pm 0.19 *$ & $9.97 \pm 0.29 *$ \\
\hline $\begin{array}{l}45 \text { day affection with tobacco smoke + } \\
\text { 24 hours sodium nitrite poisoning }\end{array}$ & $7.74 \pm 0.35 *$ & $9.35 \pm 0.32 *$ & $10.94 \pm 0.21^{*}$ \\
\hline $\begin{array}{l}45 \text { day affection with tobacco smoke + } \\
72 \text { hours sodium nitrite poisoning }\end{array}$ & $8.87 \pm 0.21 *$ & $10.50 \pm 0.26^{*}$ & $10.90 \pm 0.31^{*}$ \\
\hline
\end{tabular}

Note: here and in the following tables * - significant changes between the intact rats and the rats affected with tobacco smoke $(\mathrm{p} \leq 0.05)$.

the end of the experiment end ( $45^{\text {th }}$ day of tobacco affection) were administered with sodium nitrite, the content of IL-6 increased in 4.6 times.

Thus, the immature rats were the most sensitive to smoke and both toxins, inflammation in them was developed the fastest and most actively.

The research of anti-inflammatory cytokines (IL-4) content in the studied rats affected with xenobiotics was useful. The results are presented in Figure 1.

The rate of inflammatory cytokines activity is the lowest in the immature rats, in the simul taneous use of sodium nitrite and smoke the content of IL-4 reaches $45 \%$ compared to the norm (on $45^{\text {th }}$ day of smoke intoxication and $72^{\text {nd }}$ hour of sodium nitrite poisoning), as presented in Figure 1.

In the immature and senile rats the content of this indicator after the affection with tobacco smoke was on the same level, $68 \%$ of the intact animals' rate. The use of sodium nitrite as an additional toxicant contributed to the disorders in the system of anti-inflammatory cytokines formation. In the old rats after sodium nitrite application, the IL-4 content in tabaco smoke intoxicated rats decreased by $45 \%$ and was $55 \%$ of norm, in the mature rats in this period it was $59 \%$.

Therefore, sodium nitrite poisoning of rats with underlying tobacco intoxication leads to the imbalance in the system of pro-/anti-inflammatory cytokines, pro-inflammatory indicators are predominant.

\section{Discussion}

It is established that after getting into the human body nitrates are restored to nitrites, which lead to the activation of methaemoglobin formation that causes tissue hypoxia. According to literature [7], sodium nitrite in contact with oxyhaemoglobin is a powerful generator of active radicals: $\mathrm{HO}_{2}, \mathrm{O}_{2} \mathrm{OH}, \mathrm{NO}_{2}$. These metabolites damage biological systems, have a significant cytotoxic action, initiate the process of lipid peroxidation, can reveal a strong oxidizing action interacting with $\mathrm{SH}$-groups of proteins, reduced forms of nucleotides, physiologically active compounds [14].

In the pathogenesis of various diseases, inflammation caused by immune mechanisms is of great importance that is confirmed by the numerous experimental studies [15]. Inflammation is developed in response to damage and penetration into tissues of pathogens with

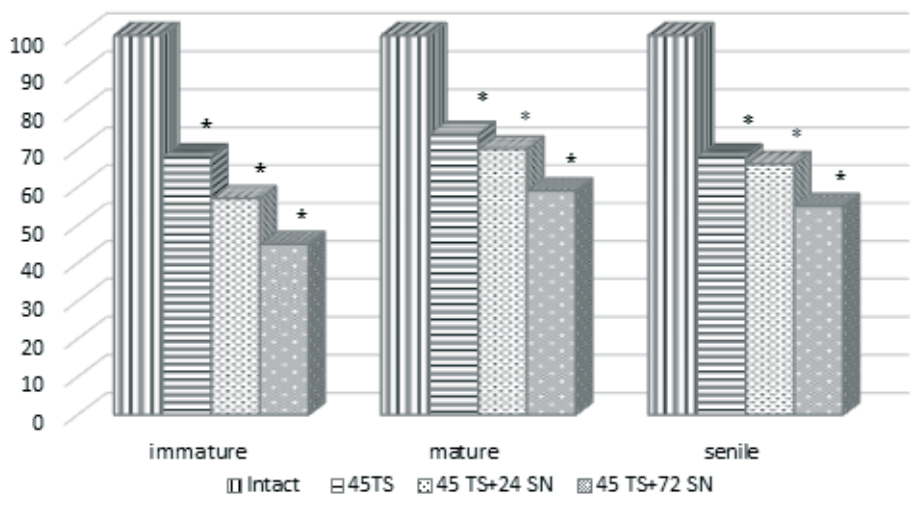

Fig. 1. The content of anti-inflammatory cytokines (IL-4) in blood serum of the rats of different age groups affected by sodium nitrite with underlying 45 -day tobacco intoxication, \%. 
participation of pro-inflammatory cytokines: IL-1, TNF-a, IL-6, IL-8 chemokines. In case of local reactions violation, protective inflammatory response is intensified, synthesis of cytokines is increased; they get into the bloodstream and effect at a system level. In this case pro-inflammatory cytokines affect almost all organs and body systems. [15]

The cytokine imbalance is important for the initiation and progression of inflammation in the body, but the role of cytokines during chronic inflammatory reactions still remains to be determined.

\section{References}

1. Bakharev VS, Kortsova OL, Zharikova MO, Gushchin AV. Bad habits as a factor in the formation of impact of environmental risks. Environmental Safety. 2009;1(5):68-72.

2. Behera $\mathrm{S}$, Xian H, Balasubramanian R. Human health risk associated with exposure to toxic elements in mainstream and sidestream cigarette smoke. Science of the Total Environment. 2014;472(15): 947-56.

3. Hagstad S, Bjerg A, Ekerljung L, Backman $\mathrm{H}$, Lindberg A, Ronmark E, Lundback B. Passive smoking exposure is associated with increased risk of COPD in never smokers. Chest. 2014;145(6):1298-304.

4. Goraca A, Scibska B. Plasma antioxidant status in healthy smoking and non-smoking men. Bratisl Lec Listy. 2005;106(10):301-306.

5. Kiral F, Ulutas PA, Fidanci UR. Lipid peroxidation and antioxidant enzymes in rats affected with cigarette smoke. Ancara Univ Vet Fac Derg. 2008; 117(6):145-148.

6. Yokus B, Mete N, Cakir UD, Toprak G. Effects of active and passive smoking on antioxidant enzymes and antioxidant micronutrients. Biotechnol Eq. 2005;19:117-123.

7. El-Sheikh N, Khalil F. L-Arginine and I-glutamine as immunonutrients and modulating agents for oxidative stress and toxicity induced by sodium nitrite in rats. Food and Chemical Toxicology. 2011; 49(4):758-762.

\section{Conclusions}

The affection of rats of different age with sodium nitrite with underlying tobacco intoxication leads to nitrite ion accumulation in serum and organs of animals that may be caused by activation of free radical processes in the body. The violation in ratio pro- and anti-inflammatory cytokines was determined. The most significant increase of IL- 6 in the immature rats with underlying decrease of anti-inflammatory IL-4 was proved; that is one of the causes of decreased activity of protective systems after injury.

8. Green C, David A, Golawski J. Analysis of nitrate, nitrite and $(15 \mathrm{~N})$ nitrate in biological fluids. Anal Biochem. 1982;126(1):131-138.

9. Symbyrtsev AS. Cytokines - a new system of regulation of protective reactions of the organism. Cytokines and Inflammation. 2002;1(1):9-17.

10. Yrhashev TA, Karimov AI. Nitrates effect on the body of humans and animals (Review). Dushanbe: Nodyr; 2009;58.

11. Peremot SD, Smilianska MV, Wolanska A. The activity of cytokines in patients with acute coronary syndrome. Annals of Mechnikov Institute. 2010;3: 33-37.

12. Medical ethics and human rights, regulations on use of animals in biomedical experiments. Experimental and Clinical Physiology and Biochemistry. 2003;2(22):108-109.

13. Lapach SN. Statistical methods in medical and biology research using Excel in experimental study. Clinical test. Analysis of the pharmaceutical market. Kyiv: Moryon; 2000;320.

14. Holovko LL. Protective status of the organism under conditions combined effects of cadmium and lead salts and sodium nitrite. Medical Chemistry. 2004;6(3):176.

15. Rahyno YI, Chernyavskyy AM, Polonskaya Y. Inflammatory and destructive changes in the process of vulnerable atherosclerosis plaque modification. Cardiology. 2007;9:62-66. 